\title{
Dissociation of Haloperidol, Clozapine, and Olanzapine Effects on Electrical Activity of Mesocortical Dopamine Neurons and Dopamine Release in the Prefrontal Cortex
}

Gian Luigi Gessa, M.D., Paola Devoto, Ph.D., Marco Diana, M.D., Giovanna Flore, Ph.D., Miriam Melis, Ph.D., and Marco Pistis, M.D.

The aim of the present study was to compare the effects of the typical antipsychotic haloperidol and the atypical antipsychotics clozapine and olanzapine on both extracellular dopamine (DA) levels in the medial prefrontal cortex ( $m P F C)$ as well as electrical activity of mesoprefrontal DA (mPFC-DA) neurons. Extracellular single unit recordings and microdialysis experiments were carried out in different groups of chloral hydrate anesthetised rats under identical experimental conditions. Intravenous administration of haloperidol, clozapine, and olanzapine increased the firing rate and burst activity of antidromically-identified mPFC-DA neurons; maximal increase in firing rate of approximately 140,155, and $70 \%$, was produced by haloperidol, clozapine, and olanzapine at doses of $0.2,2.5$, and $1 \mathrm{mg} / \mathrm{kg}$, i.v., respectively. Intravenous administration of the same doses increased extracellular DA levels in mPFC by $20 \%, 190 \%$, and $70 \%$, respectively. Moreover, while haloperidol and olanzapine increased extracellular levels of the deaminated DA metabolite
DOPAC, by $60 \%$ and $40 \%$, respectively, clozapine was totally ineffective. The D1 receptor antagonist SCH 23390 modified neither DA output nor neuronal firing. To determine whether the effect of the three antipsychotics on $D A$ release might depend on a direct action on the $M P F C$, rats were perfused locally via inverse dialysis in the $m P F C$ at concentrations ranging from $10^{-6}$ to $10^{-4} \mathrm{M}$. While clozapine and olanzapine increased extracellular DA concentrations by up to $400 \%$ of basal level, haloperidol was totally ineffective. The results obtained from this study indicate that the rank potency of the three antipsychotics in stimulating the firing rate of DA neurons projecting to $m P F C$, correlates with their affinity for D2 receptors and doses used clinically. On the other hand, their stimulating effect on DA release does not correlate with their effect on neuronal firing but depends on a direct action on the mPFC.

[Neuropsychopharmacology 22:642-649, 2000] (C) 2000 American College of Neuropsychopharmacology. Published by Elsevier Science Inc.
KEY WORDS: Antipsychotics; Dopamine; Electrophysiology; Microdialysis; Prefrontal cortex; Schizophrenia

From the "B.B. Brodie" Department of Neuroscience, University of Cagliari, Italy (GLG, PD, GF, MM); Department of Drug Sciences, University of Sassari, Italy (MD); and Neuroscience S.C.AR.L., Cagliari, Italy (MP).

Address correspondence to: Prof. G.L. Gessa, Dept. of Neuroscience "B.B. Brodie", University of Cagliari, Via Porcell, 4, 09124 Cagliari, Italy.

Received May 24, 1999; revised December 8, 1999; accepted December 28, 1999.
The atypical antipsychotics clozapine and olanzapine have been reported to produce a greater increase in extracellular dopamine (DA) concentration in the medial prefrontal cortex (mPFC) than in the striatum and nucleus accumbens, whereas the prototype typical antipsychotic haloperidol is considered to be much less effective in increasing extracellular DA levels in the mPFC than in the nucleus accumbens and striatum (Moghaddam and Bunney 1990; Nomikos et al. 1994; Pehek and Yamamoto 1994; Volontè et al. 1997; Kuroki et al. 1999). 
Involvement of dopaminergic hypofunction in the $\mathrm{mPFC}$ has been suggested in the pathogenesis of both negative symptomatology and cognitive deficits observed in schizophrenia (Meltzer and Stahl 1976; Snyder 1976; Weinberger 1987; Daniel et al. 1991; Deutch 1992; Lidow et al. 1998). Accordingly, the ability of clozapine and olanzapine to increase DA release in this area has been suggested to mediate their efficacy in improving such disturbances in schizophrenia. However, the mechanism by which the two atypical antipsychotics selectively increase DA release in the $\mathrm{mPFC}$ is not clear.

To our knowledge, no studies have been performed to examine whether the stimulating effect of clozapine and olanzapine on DA release in the $\mathrm{MPFC}$ is due to an increased activity of mPFC-DA neurons or whether it depends on a direct action on the mPFC. Indeed, while various studies have investigated the effect of atypical antipsychotics on the electrical activity of DA neurons in the ventral tegmental area (VTA) (Hand et al. 1987; Stockton and Rasmussen 1996), to date, none of them has analysed the effect of these compounds on the electrical activity of antidromically identified mPFC-DA neurons, which constitute a small percentage of the total VTA DA neurons (Oades and Halliday 1987).

The aim of the present study was to compare, under the same experimental conditions, the effect of the prototype typical antipsychotic haloperidol with that of the atypical antipsychotics clozapine and olanzapine on the electrical activity of antidromically identified mPFCDA neurons on one hand, and on the release of DA in the mPFC on the other.

\section{METHODS}

Male Sprague Dawley albino rats (Charles River, Como, Italy) weighing 200-280 $\mathrm{g}$ were used in all experiments. All animals were kept on a 12/12 h light/dark cycle with food and water available ad libitum. Experimental protocols were approved by the Ethical Committee (EC) at the University of Cagliari and performed in strict accordance with the $\mathrm{EC}$ regulations for the care and use of experimental animals (CEE NE86/609).

\section{Electrophysiological Experiments}

The rats were anaesthetised with chloral hydrate (400 $\mathrm{mg} / \mathrm{kg}$, i.p.) which was supplemented as required by means of intravenous (i.v.) infusion during the experiment. Thereafter, the femoral vein was cannulated for i.v. administration of pharmacological agents and animals were placed in a stereotaxic apparatus (Kopf). Body temperature was maintained constant at $38 \pm 1^{\circ} \mathrm{C}$ by means of an electrically controlled heating pad. The scalp was retracted and two burr holes were drilled, one for the placement of a recording electrode above the VTA (AP $2 \mathrm{~mm}$ anterior to lambda; L 0.3-0.5 mm from midline, and 6.5-8 $\mathrm{mm}$ from cortical surface) (Paxinos and Watson 1986) and the other to introduce a Formvar coated stainless-steel bipolar electrode for antidromic identification in the mPFC (AP 2.7-3.2 mm anterior to bregma; L $0.9 \mathrm{~mm}$ from midline; V 2-3.5 mm from dura mater).

Stimuli consisting of monophasic rectangular pulses (0.1-2.0 mA; 0.1-0.5 ms; $0.8 \mathrm{~Hz}$ ) were generated. The stimulating current was monitored on the oscilloscope. DA neurons were identified according to well established electrophysiological characteristics (Bunney et al. 1973) and by antidromic activation from the mPFC including collision of an antidromically-elicited spike with spontaneously occurring action potentials (Lipski 1981; Gariano and Groves 1988). The extracellular neuronal signal from single neurons was amplified (Neurolog System, Digitimer Ltd, Welwyn Garden City, UK) and displayed on a digital oscilloscope (Philips pm 3305) before storage on magnetic tape for off-line analysis of the data. The firing rate and pattern analysis were performed using a Commodore 128 computer programmed in machine language as already described (Diana et al. 1989). Burst firing consists of trains of two or more spikes occurring within a interval shorter than $80 \mathrm{~ms}$ and followed by a period of inactivity longer than $160 \mathrm{~ms}$ (Grace and Bunney 1984). Burst firing was measured as the mean number of spikes within a burst (spikes/burst), and as the total percentage of firing occurring in burst (\% of burst firing).

Only one cell was recorded per rat. Recordings were made only from cells whose electrophysiological characteristics matched those previously established by Grace and Bunney (1983) (e.g.: (i) action potentials with bi- or triphasic waveforms with a width of $2.5-4 \mathrm{msec}$ in duration and an inflection (notch) in the initial positive component; (ii) a typically slow spontaneous firing rate of 1-10 Hz; and (iii) occurrence of single and burst spontaneous firing pattern), and antidromic activation from the PFC according to Lipski (1981) and Gariano et al. (1989) ((i) long and fixed antidromic latency; and (ii) collision test: collision of an antidromically-elicited spike with spontaneously occurring action potentials). The hit-rate was very low, being about $20 \%$.

Clozapine (Sandoz, Milan, Italy) and olanzapine (Eli Lilly, Indianapolis, IN, USA), haloperidol (Lusofarmaco, Milano, Italy), and SCH 23390 (Research Biochemical, Inc., Natick, MA) were dissolved in 5\% tartaric acid and then diluted in buffered saline solution. Since vehicle alone was ineffective in altering the firing rate, vehicle control was not included in the present study. Injection volumes were $1 \mathrm{ml} / \mathrm{kg}$ of body weight.

Following the collection of antidromic data for each neuron, electrical stimulation was interrupted and the spontaneous firing rate was recorded for $5 \mathrm{~min}$ to establish a baseline measure of firing rate. Drugs were then 
administered, i.v. at exponentially increasing doses at $120 \mathrm{~s}$ intervals. Changes in firing rate and burst rate were calculated by averaging the effects of the drugs for the 2 min period following drug or vehicle administration and comparing them to the mean of the pre-drug baseline. Dose-response relationships for each antipsychotic were iteratively fitted by the use of Graph Pad Prism, Version 1.03, with four parameters logistic equation

$$
y=\min +\frac{M A X-\min }{1+10^{\log \left(E D_{50}-x\right)^{*} n}}
$$

where $y$ is the percent of firing rate; min and $M A X$ are the minimum and maximal percent increase of firing rate, respectively; $E D_{50}$ is the dose of antipsychotic producing the half-maximal response; $x$ is the logarithmic of dose; and $n$ is the Hill slope of the curve.

Statistical significance was evaluated on raw data by analysis of variance (ANOVA) for repeated measures, followed by Newman-Keuls test as post-hoc. Burst data were analysed using Students' t-test. Basal data distribution was verified by Chi square test.

\section{Microdialysis Experiments}

Rats were anesthetised with Equithesin ( $5 \mathrm{ml} / \mathrm{kg}$, i.p.) and placed in a Kopf stereotaxic frame. The skull was exposed and a hole was drilled through the two temporal bones for insertion in the MPFC (AP +2.7, V - 2.6 from bregma, according to Paxinos and Watson (1986) atlas) of the transversal dialysis probe (AN 69-HF; Hospal-Dasco, Bologna, Italy; cut-off 20,000 Dalton, in vitro recovery about $30 \%$ ). After $20-24 \mathrm{~h}$, an artificial cerebrospinal fluid (aCSF) $(147 \mathrm{mM} \mathrm{NaCl}, 4 \mathrm{mM} \mathrm{KCl}$, $1.5 \mathrm{mM} \mathrm{CaCl}_{2}$, pH 6-6.5) was pumped with a CMA/100 microinjection pump (Carnegie Medicine, Sweden) through the dialysis tube at a constant rate of $2.3 \mu \mathrm{l} /$ min. DA and dihydroxyphenylacetic acid (DOPAC) were estimated in samples collected every $20 \mathrm{~min}$ and directly injected into a HPLC apparatus, consisting of a Gilson pump, a 7125 Rheodyne injector, a Hewlett Packard series 1100 column thermostat equipped with a Symmetry column $(\mathrm{C} 18,5 \mu \mathrm{m}, 4.6 \times 150 \mathrm{~mm})$, and an ESA Coulochem II detector. Data were recorded using a Waters 746 Data Module integrator, and quantified according to standard calibration.

The mobile phase for analysis of DA and DOPAC consisted in $50 \mathrm{mM}$ sodium acetate, $0.2 \mathrm{mM}$ EDTA, 0.43 $\mathrm{mM}$ sodium octyl sulphate, $14 \%$ methanol, $\mathrm{pH} 4.9$ with acetic acid, delivered at $1.0 \mathrm{ml} / \mathrm{min}$; column temperature was set at $34^{\circ} \mathrm{C}$, the Coulochem analytical cell first electrode was set at $+350 \mathrm{mV}$, and the second at -180 $\mathrm{mV}$. Once a stable DA baseline had been achieved, rats were anesthetized with chloral hydrate $(400 \mathrm{mg} / \mathrm{kg}$, i.p), the femoral vein was cannulated for i.v. administration of pharmacological agents and rats were placed in a stereotaxic apparatus. aCSF perfusion and sample collection were recommenced and, subsequent to obtaining of at least three consecutive samples differing by no more than $10 \%$, drugs were intravenously administered; chloral hydrate was supplemented as needed by means of i.v. infusion throughout the experiment. For inverse dialysis administration, drugs were dissolved in $5 \mu \mathrm{l}$ of glacial acetic acid, then diluted in aCSF and buffered to $\mathrm{pH}$ 6-6.5 with $\mathrm{NaOH}$. Pilot experiments showed that neither vehicle administration nor the perfusion with buffered aCSF modified basal DA and DOPAC extracellular levels.

For microdialysis experiments, the raw basal data (pg) were analysed by Chi-square test, then normalised to percent of mean basal level of each rat, because no significative difference was found between treatment groups. Statistical significance was then evaluated by analysis of variance (ANOVA) for repeated measures, followed by Newman-Keuls test as post-hoc.

\section{RESULTS}

As shown in Figures 1 and 2, i.v. administration of haloperidol $(n=6 ; 0.025-0.2 \mathrm{mg} / \mathrm{kg})$, clozapine $(n=6 ; 0.062-$ $2.5 \mathrm{mg} / \mathrm{kg})$, and olanzapine $(n=6 ; 0.125-1 \mathrm{mg} / \mathrm{kg})$ produced a dose-related increase in the firing rate of antidromically identified mPFC-DA neurons.

Basal firing rates were $1.49 \pm 0.06,1.46 \pm 0.2,2.48 \pm$ $0.6 \mathrm{~Hz}$ for haloperidol, clozapine, and olanzapine groups, respectively. Basal value distribution did not differ significantly between groups (Chi square test).

Following the highest cumulative dose tested, haloperidol $(0.2 \mathrm{mg} / \mathrm{kg})$, clozapine $(5 \mathrm{mg} / \mathrm{kg})$, and olanzapine $(1 \mathrm{mg} / \mathrm{kg})$ maximally increased the firing rate by $138.55 \pm 8.44,154.62 \pm 10.3$, and $68.92 \pm 13.77 \%$, respectively [(ANOVA for repeated measures: haloperidol $(\mathrm{F}(4,25)=17.26 ; p<.01)$, clozapine $(\mathrm{F}(3,20)=14.22$; $p<.01)$, and olanzapine $(\mathrm{F}(4,25)=7.37 ; p<.01)$, respectively] (Figure 1).

All antipsychotics tested produced a significant increase in the percent of burst firing when compared with pre-drug levels, with values of $70.6 \pm 6.2$ vs. $29.9 \pm$ $9.2,22.0 \pm 11.3$ vs. $6.5 \pm 3.3$, and $57.7 \pm 13.4$ vs. $32.3 \pm$ 6.7 for haloperidol, clozapine, and olanzapine, respectively [Students' $\mathrm{t}$-test, haloperidol $(n=6, \mathrm{t}=3.66 ; p<$ $.01)$, clozapine $(n=6, \mathrm{t}=4.89 ; p<.01)$, and olanzapine $(n=6, t=2.92 ; p<.05)]$ (Figure 3, top). Administration of the three antipsychotics also significantly increased the number of spikes per burst when compared with pre-drug level, at values of $4.2 \pm 0.5$ vs. $2.6 \pm 0.2,2.33 \pm$ 0.1 vs. $1.86 \pm 0.3$, and $3.88 \pm 1.38$ vs. $2.5 \pm 0.5$ for haloperidol, clozapine, and olanzapine, respectively [Students' $\mathrm{t}$-test, haloperidol $(n=6, \mathrm{t}=3.66 ; p<.01)$, clozapine $(n=6, \mathrm{t}=4.89 ; p<.01)$, and olanzapine $(n=6, \mathrm{t}=$ 2.92; $p<.01)$ ] (Figure 3, bottom). 


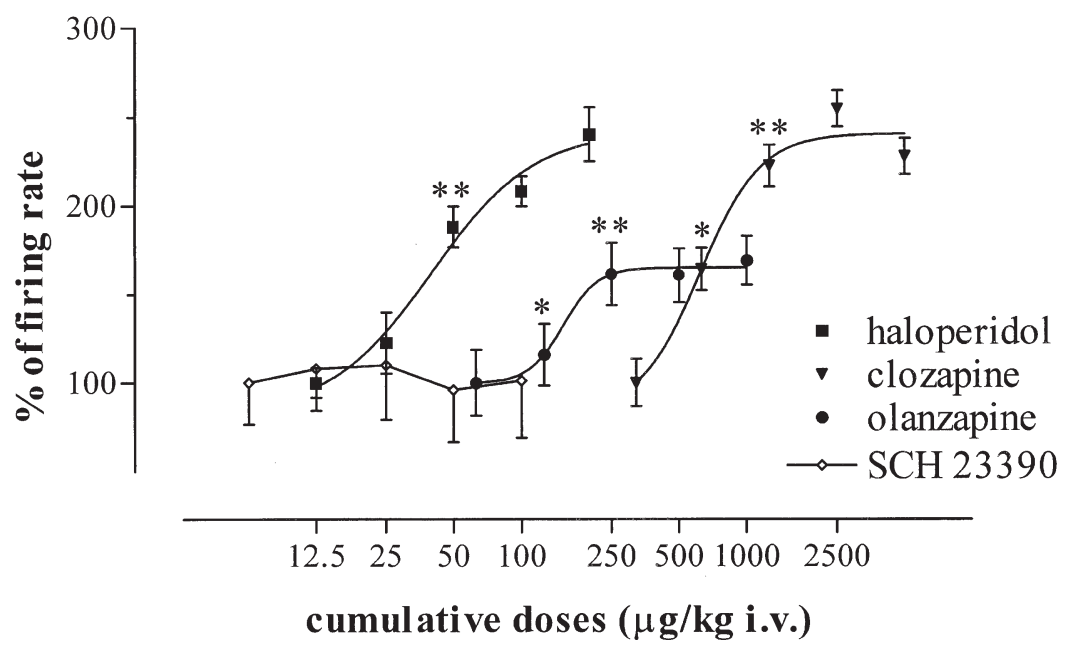

Figure 1. Dose-response curves showing the stimulating effect (ANOVA, see Results) of cumulative doses of antipsychotic drugs on the firing rate of VTA DA neurons antidromically identified from the PFC in chloral hydrate-anesthetised rats. Data (mean \pm S.E.M.) are expressed as percentages of the basal firing rate. ${ }^{*} p<.05 ;{ }^{* *} p<.01$ with respect to pre-drug level (Newman-Keuls' test).

On the contrary, i.v. administration of the selective DA $D_{1}$ receptor antagonist SCH $23390(n=6$; 0.012-0.1 $\mathrm{mg} / \mathrm{kg}$ ) did not produce any change in electrical activity (firing pattern and rate) of mPFC-DA neurons in chloral hydrate-anaesthetised rats, with a basal firing rate $2.17 \pm 0.44$ and $2.39 \pm 0.42 \mathrm{~Hz}$ before and after administration, respectively (ANOVA for repeated measures, $n=6, F(4,25)=0.32 ; p>.05$ ) (Figure 1). In order to match the conditions of the microdialysis experiments, additional experiments were carried out in rats who had been anesthetised with equithesin $24 \mathrm{~h}$ prior to the electrophysiological recordings. Results from these experiments (two for each drug treatment) did not differ from the above reported experiments (data not shown).

The effect of the three neuroleptics on DA release in the mPFC was determined by microdialysis in rats kept under the same conditions as for electrophysiological recording; namely, the day after insertion of a transversal dialysis probe in the MPFC, animals were anesthetised with chloral hydrate and placed in the stereotaxis apparatus (see Methods).

The mean \pm SEM basal dialysate concentration of DA obtained from all animals before and after anaesthesia was $3.66 \pm 0.19$ and $3.59 \pm 0.20 \mathrm{pg} / 40 \mu \mathrm{l}$, respectively. As shown in Figure 4, the i.v. administration of doses of haloperidol $(0.2 \mathrm{mg} / \mathrm{kg})$ and clozapine $(1.25$ $\mathrm{mg} / \mathrm{kg}$ ), equally effective in stimulating the firing rate of mPFC-DA neurons, produced an increase in extracellular DA concentration of $21.6 \pm 11.2$ and $188.6 \pm 16.6 \%$ $(\mathrm{F}(6,62)=64.5 ; p<.01)$, respectively. However, while haloperidol increased extracellular levels of DOPAC by $62.0 \pm 18.2 \%(\mathrm{~F}(6,64)=11.86 ; p<.01)$, clozapine had no significant effect. The i.v. administration of olanzapine at a dose of $0.25 \mathrm{mg} / \mathrm{kg}$, which had stimulated the firing rate by about $50 \%$, increased DA and DOPAC release by $71 \pm 4.6(\mathrm{~F}(6,52)=25.35 ; p<.01)$ and $43.1 \pm$ $14 \%(\mathrm{~F}(6,55)=5.93 ; p<.01)$, respectively. SCH 23390, i.v. administered at a dose of $0.1 \mathrm{mg} / \mathrm{kg}$, failed to mod- ify DA and DOPAC levels in the mPFC. Also vehicle i.v. injection was devoid of any effect (data not shown).

To determine whether the effect of the three antipsychotics on extracellular DA and DOPAC levels was dependent on a direct action in the $\mathrm{mPFC}$, the drugs were infused locally in the MPFC via inverse dialysis.

As shown in Figure 5, perfusion of clozapine and olanzapine into the mPFC produced a concentrationdependent increase in extracellular DA levels. Maximal increases of $464 \%$ for clozapine $(\mathrm{F}(9,58)=39.8 ; p<.01)$ and $374 \%$ for olanzapine $(\mathrm{F}(9,62)=29.19 ; p<.01)$ were produced by drug concentrations of $10^{-4} \mathrm{M}$. In contrast, haloperidol, locally perfused, failed to modify DA levels with the exception of the highest concentration tested which decreased DA by up to $68.4 \%(\mathrm{~F}(9,50)=$ 18.6; $p<.01)$. DOPAC levels were decreased up to a maximum of $23.7 \% \mathrm{~F}(9,59)=2.76 ; p<.05)$ by the highest clozapine concentration tested, but they were not modified by the other treatments.

\section{DISCUSSION}

Results obtained in the present study provide the first evidence that haloperidol, clozapine, and olanzapine share the ability to stimulate the electrical activity of mPFC-DA neurons.

Previous reports studied the effect of acute and chronic administration of typical and atypical antipsychotics on the electrical activity of VTA DA cells (Chiodo and Bunney 1983; White and Wang 1983; Hand et al. 1987; Stockton and Rasmussen 1996), of which mPFC-DA neurons constitute only a small fraction (Oades and Halliday 1987). Therefore, results obtained from unidentified VTA DA neurons do not necessarily apply to mesocortical ones (Melis et al. 1999). With regard to nigro-striatal DA neurons, neuroleptic-induced increase in firing rate is considered to represent a com- 

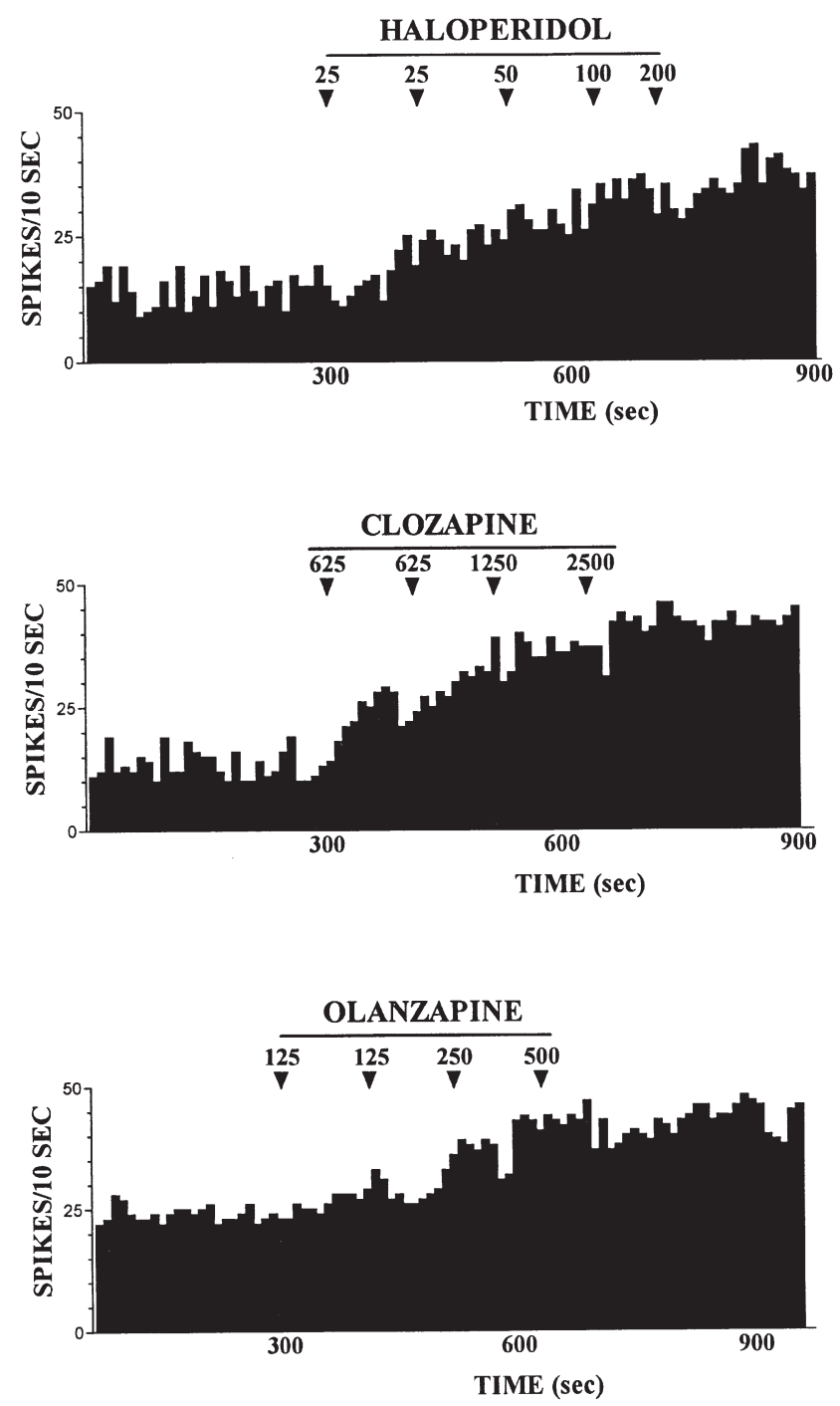

Figure 2. Examples of the effects produced by cumulative doses of the three antipsychotics tested on DA neurons antidromically-identified from the PFC and recorded from chloral hydrate-anesthetised rats. The panel depicts the effect induced by the administration of haloperidol (top), clozapine (middle), and olanzapine (bottom) on DA neurons. Arrows indicate time of injection. Numbers above arrows indicate dosages expressed in $\mu \mathrm{g} / \mathrm{kg}$, i.v.

pensatory feedback response to blockade of both preand postsynaptic $\mathrm{D}_{2}$ receptors (Pucak and Grace 1994).

Assuming that the same mechanism operates in the mPFC pathway, our results should indicate that the increased activity of DA neurons produced by typical and atypical antipsychotics reflects a blockade of the above mentioned receptors (Wolf and Roth 1987). In agreement with this interpretation, the rank order of potency of the three antipsychotics in increasing DA firing correlates well with their affinity for $\mathrm{D}_{2}$ receptors (Seeman et al. 1976; Creese et al. 1976).
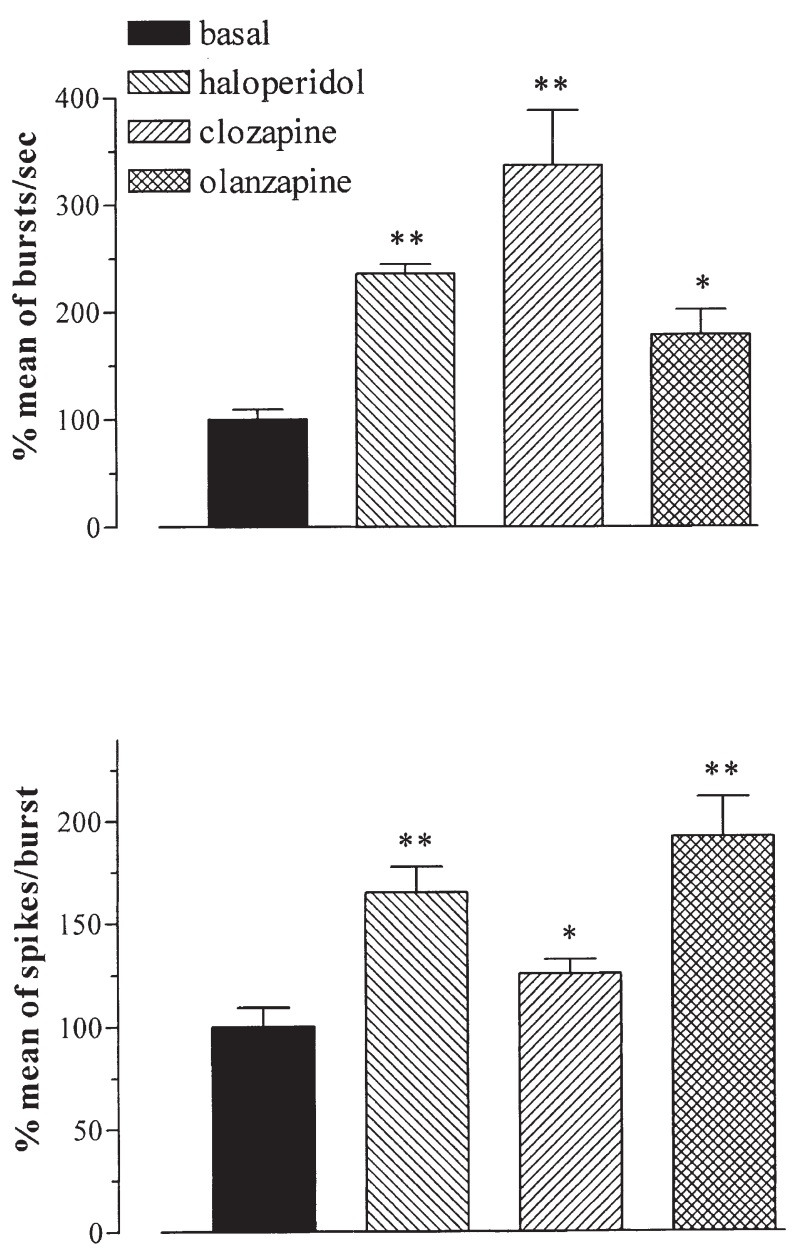

Figure 3. Effect of antipsychotics on the percentage of burst firing (top panel), and spikes / burst (bottom panel) of VTA DA neurons antidromically identified from the PFC in chloral hydrate-anesthetised rats. All effects were observed at the highest cumulative dose administered and expressed as the percentage of the baseline (mean \pm S.E.M.). ${ }^{*} p<.01$; ** $p<.05$ with respect to pre-drug level (Students' t-test).

On the other hand, blockade of $\mathrm{D}_{1}$ receptors does not seem to be involved in the stimulant action produced by antipsychotics on mPFC-DA neurons since the selective $\mathrm{D}_{1}$ receptor antagonist, $\mathrm{SCH}$ 23390, modified neither the electrical activity of DA neurons nor extracellular DA and DOPAC concentrations in the mPFC. Thus, the stimulant effect on DA neurons seems to reflect the common property of typical and atypical antipsychotics to block $\mathrm{D}_{2}$ receptors. Moreover, the rank order of potency of the three antipsychotics in stimulating DA neurons correlates with their clinical dosage and the ability of typical and atypical antipsychotics to control positive symptoms of schizophrenia.

In contrast to the findings obtained in the electrophysiological experiments, the results of the dialysis experiments revealed qualitative differences between ha- 

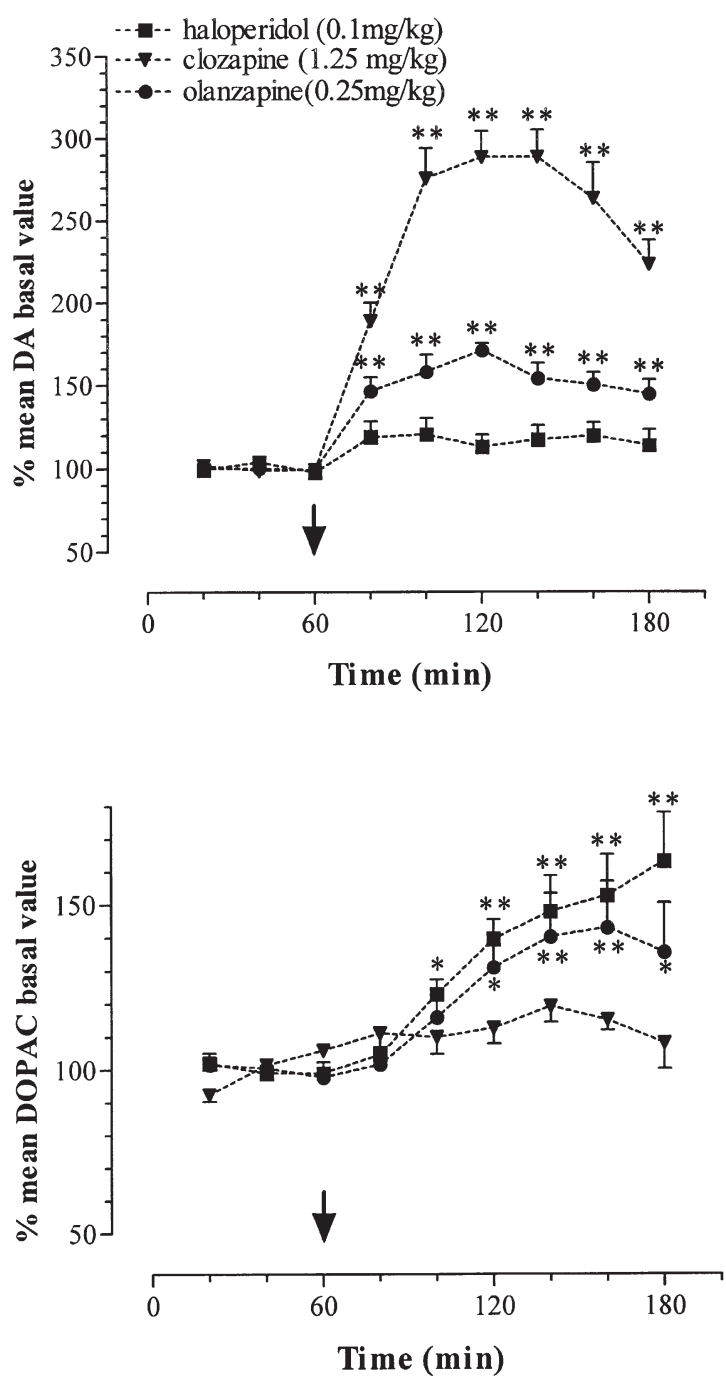

Figure 4. Effect of i.v. administration of antipsychotics on extracellular DA and DOPAC levels in the $\mathrm{MPFC}$, in chloral hydrate-anesthetized rats. Data (mean \pm S.E.M. of at least six rats) are expressed as percentages of the mean basal concentration (DA: $3.66 \pm 0.20,3.26 \pm 0.38,3.37 \pm 0.40,3.07 \pm$ 0.36; DOPAC: $132.66 \pm 18.23,157.66 \pm 18.94,218.11 \pm 24.54$, $177.25 \pm 36.59 \mathrm{pg} / 40 \mu \mathrm{l}$ sample for haloperidol, clozapine, olanzapine, and SCH 23390, respectively). Arrows indicate the time of drug administration. ${ }^{*} p<.05 ;{ }^{* *} p<.01$ with respect to pre-drug level (Newman-Keuls' test).

loperidol and the atypical antipsychotics, olanzapine and clozapine, in their ability to modify extracellular DA concentrations in the mPFC. Accordingly, intravenous administration of clozapine at doses equally effective in stimulating DA neurons, markedly increased DA output, whereas haloperidol produced only a modest increase. Furthermore, olanzapine, at doses less effective than haloperidol in stimulating DA neurons, increased DA levels similarly to clozapine.

These results suggest that olanzapine and clozapine induced DA release does not depend on their stimulat-
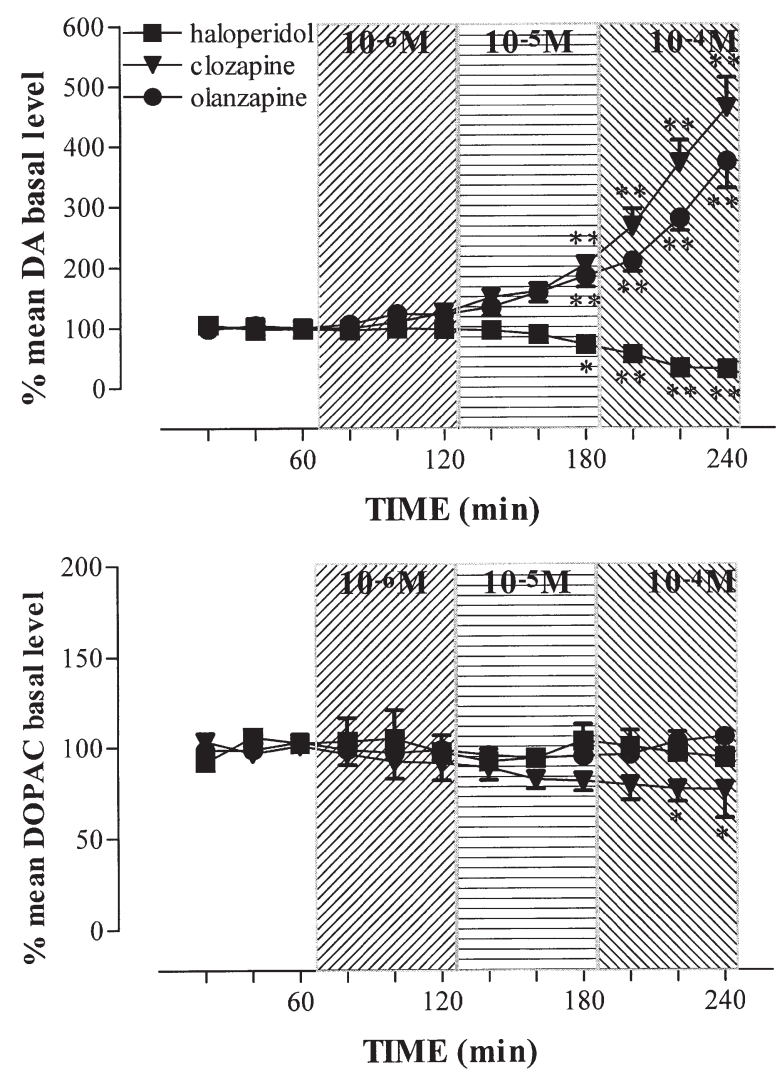

Figure 5. Effect of antipsychotics, administered by inverse dialysis, on extracellular DA and DOPAC mPFC levels in chloral hydrate-anesthetised rats. Three consecutive increasing concentrations were used for each drug. Data (mean \pm S.E.M. of at least 6 rats) are expressed as percentages of the mean basal concentration. (DA: $2.19 \pm 0.26,3.09 \pm 0.61,3.11$ \pm 0.38; DOPAC: $186.29 \pm 8.37,216.78 \pm 17.93,145.94 \pm$ $16.60 \mathrm{pg} / \mathrm{sample}$ for haloperidol, clozapine, and olanzapine, respectively) ${ }^{*} p<.05 ;{ }^{* *} p<.01$ with respect to pre-drug level (Newman-Keuls' test).

ing effect on DA neurons and suggest that it may be mediated by a local action in the mPFC. This possibility is supported by the results obtained in experiments involving local perfusion of the three antipsychotics in the mPFC, showing that while haloperidol slightly decreased DA output, clozapine and olanzapine markedly augmented DA release in the $\mathrm{MPFC}$.

Another possibility could be that antipsychoticsinduced systemic effects on DA extracellular levels are due to both a local action on mPFC and a stimulation of VTA cell firing. Thus, clozapine and olanzapineinduced increments would be the sum of effects occurring at the soma and at the terminal region of mesoprefrontal DA neurons. Conversely, the lack of effect of haloperidol would represent the algebric sum of an inhibitory local action in the $\mathrm{mPFC}$ and an increased firing-dependent release. This last effect is indirectly supported by the increase in extracellular DOPAC levels observed after ha- 
loperidol. Clozapine and olanzapine interact with a broad range of receptors, including $\mathrm{D}_{1}, \mathrm{D}_{2}, \mathrm{D}_{4}, 5 \mathrm{HT}_{2 \mathrm{~A}}$ serotoninergic and $\alpha$-adrenergic receptors, each of which has been suggested to be involved in the ability of these antipsychotics to increase DA release in the mPFC (Rollema et al. 1997; Brunello et al. 1995; Schmidt and Fedayel 1995; Pehek 1996). However, the mechanism by which such interactions might result in increased DA release in the $\mathrm{mPFC}$ is still unclear.

The effect of the antipsychotics on DOPAC concentrations might offer a hint to clarify this problem. The three antipsychotics differentially modified extracellular concentrations of DOPAC in the mPFC. Systemically administered haloperidol and olanzapine increased DOPAC concentrations while clozapine was ineffective.

The DA metabolite is considered to represent intraneuronally deaminated DA, so that an increase in its extracellular concentrations may reflect increase in release and reuptake of DA by nerve terminals. Accordingly, it might be suggested that, by activating DA neurons, haloperidol evokes an increased DA release into the synaptic cleft, but DA is rapidly removed from the synapse into the nerve terminal by means of a highly efficient reuptake mechanism. On the other hand, clozapine might interfere with the reuptake process thereby reducing DA deamination and enhancing DA that escapes from the synaptic cleft (Lee et al. 1997). This possibility is supported by the finding that clozapine, locally perfused, markedly increased DA output but reduced DOPAC levels. However, this mechanism does not seem to apply to olanzapine which increased both extracellular DA and DOPAC, suggesting that other factors which are not yet apparent may also be involved.

For example, considering that the MPFC is densely innervated by ascending noradrenergic neurons, the possibility that extracellular DA and DOPAC in the mPFC might originate from noradrenergic neurons should also be considered (Fadda et al. 1984; Scatton et al. 1984; Li et al. 1998). Irrespective of the mechanisms involved, the ability of olanzapine and clozapine to increase DA release in the $\mathrm{mPFC}$ raises the important problem of the functional consequences of this effect. If one assumes that $D_{2}$ receptors are blocked, it should also be concluded that endogenously released DA should act on $D_{1}$ receptors, for which clozapine and olanzapine have a relatively weak affinity (Bymaster et al. 1999) and which are densely localized in the frontal cortex (Sawaguchi and Goldman-Rakic 1991).

In light of the overall findings, we might speculate that the common therapeutic effect of typical and atypical antipsychotics on the positive symptomatology in schizophrenia is related to their $\mathrm{D}_{2}$ receptor blockade, as reflected by increased firing rate of DA neurons, whereas the increase in DA output onto $\mathrm{D}_{1}$ receptors in the $\mathrm{mPFC}$ might be responsible for the improvement of negative and cognitive symptomatology elicited by atypical antipsychotics.

\section{ACKNOWLEDGMENTS}

The authors thank Mr. Stefano Aramo for his skilled technical assistance and the company Ely Lilly for the gift of olanzapine.

\section{REFERENCES}

Brunello N, Masotto C, Steardo L, Markstein R, Racagni G (1995): New insight into the biology of schizophrenia through the mechanism of action of clozapine. Neuropsychopharmacology 13:177-213

Bunney BS, Walters JR, Roth RH, Aghajanian GK (1973): Dopaminergic neurons: effect of antipsychotic drugs and amphetamine on single cell activity. Pharmacol Exp Ther 185:560-571

Bymaster F, Perry KW, Nelson DL, Wong DT, Rasmussen K, Moore NA, Calligaro DO (1999): Olanzapine: A basic science update. Br J Psychiatry 174(37):S36-S40

Chiodo LA, Bunney BS (1983): Typical and atypical neuroleptics: Differential effects of chronic administration on the activity of A9 and A10 midbrain dopaminergic neurons. J Neurosci 3:1607-1619

Creese I, Burt DR, Snyder SH (1976): Dopamine receptor binding predicts clinical and pharmacological potencies of antischizophrenic drugs. Science 192:481-483

Daniel DG, Weinberger DR, Jones DW (1991): The effect of amphetamine on regional cerebral blood flow during cognitive activation in schizophrenia. J Neurosci 11:1907-1917

Deutch AY (1992): The regulation of subcortical dopamine systems by the prefrontal cortex: Interactions of central dopamine systems and the pathogenesis of schizophrenia. J Neural Transm 36:61-89

Diana M, Garcia-Munoz M, Richards J, Freed CR (1989): Electrophysiological analysis of dopamine cells from the substantia nigra pars compacta of circling rats. Exp Brain Res 74:625-630

Fadda F, Gessa GL, Marcou M, Mosca E, Rossetti ZL (1984): Evidence for dopamine autoreceptors in mesocortical dopamine neurons. Brain Res 283:67-72

Gariano RF, Groves PM (1988): Burst firing induced in midbrain dopamine neurons by stimulation of the medial prefrontal and anterior cingulate cortices. Brain Res 462:194-198

Gariano RF, Tepper JM, Sawyer SF, Young SJ, Groves PM (1989): Mesocortical dopamine neurons. I. Electrophysiological properties and evidence for soma-dendritic autoreceptors. Brain Res Bull 22:511-516

Grace AA, Bunney BS (1983): Intracellular and extracellular electrophysiology of nigral dopaminergic neurons. I. Identification and characterization. Neuroscience 10:301-315

Grace AA, Bunney BS (1984): The control of firing pattern in nigral dopamine neurons: Burst firing. J Neurosci 4:2877-2890 
Hand TH, Xiu-Ti H, Wang RY (1987): Differential effects of acute clozapine and haloperidol on the activity of ventral tegmental (A10) and nigrostriatal (A9) dopamine neurons. Brain Res 415:257-269

Kuroki T, Meltzer HY, Ichikawa J (1999): Effects of antipsychotic drugs on extracellular dopamine levels in rat medial prefrontal cortex and nucleus accumbens. J Pharmacol Exp Ther 288:774-781

Lee S-HL, Oh D-Y, Jung S-C, Kim Y-M, Cho H-K, Koh J-K, Lee Y-S (1997): Neuroleptic drugs alter the dopamine transporter-mediated uptake and release of dopamine: A possible mechanism for drug-induced tardive dyskinesia. Pharmacol Res 35:447-450

Li X-M, Perry KW, Wong DT, Bymaster FP (1998): Olanzapine increases in vivo dopamine and norepinephrine release in rat prefrontal cortex, nucleus accumbens and striatum. Psychopharmacology 136:153-161

Lidow MS, Williams GV, Goldman-Rakic PS (1998): The cerebral cortex: A case for a common site of action of antipsychotics. Trends Pharmacol Sci 19(4):136-140

Lipski J (1981): Antidromic activation of neurones as an analytic tool in the study of the central nervous system. J Neurosci Methods 4(1):1-32

Melis M, Diana M, Gessa GL (1999): Clozapine potently stimulates mesocortical dopamine neurons. Eur J Pharmacol 366:R11-R13

Meltzer HY, Stahl SM (1976): The dopamine hypothesis of schizophrenia: A review. Schizophr Bull 2:19-76

Moghaddam B, Bunney BS (1990): Acute effect of typical and atypical antipsychotic drugs on the release of dopamine from the prefrontal cortex, nucleus accumbens, and striatum of the rat: An in vivo microdialysis study. J Neurochem 54:1755-1760

Nomikos GG, Iurlo M, Andersson JL, Kimura K, Svensson TH (1994): Systemic administration of amperozide, a new atypical antipsychotic drug, preferentially increases dopamine release in the rat medial prefrontal cortex. Psychopharmacology 115:147-156

Oades RD, Halliday GM (1987): Ventral tegmental (A10) system: neurobiology. I. Anatomy and connectivity. Brain Res Rev 12:117-165

Paxinos G, Watson C (1986): The rat brain in stereotaxic coordinates. New York, Academic Press

Pehek EA, Yamamoto BK (1994): Differential effects of locally administered clozapine and haloperidol on dopamine efflux in the rat prefrontal cortex and caudate-putamen. J Neurochem 63:2118-2124
Pehek EA (1996): Local infusion of the serotonin antagonist ritanserin or ICS 205,930 increases in vivo dopamine release in the rat prefrontal cortex. Synapse 24(1):12-18

Pucak ML, Grace AA (1994): Evidence that systemically administered dopamine antagonists activate dopamine neuron firing primarily by blockade of somatodendritic autoreceptors. J Pharmacol Exp Ther 271(3):1181-1192

Rollema H, Lu Y, Schmidt AW, Zorn SH (1997): Clozapine increases dopamine release in prefrontal cortex by 5-HT1A receptor activation. Eur J Pharmacol 338(2):R3-R5

Sawaguchi T, Goldman-Rakic PS (1991): $\mathrm{D}_{1}$ dopamine receptors in the prefrontal cortex. Involvement in working memory. Science 251:947-950

Scatton B, Dennis T, Curet O (1984): Increase in dopamine and DOPAC levels in noradrenergic terminals after electrical stimulation of the ascending noradrenergic pathways. Brain Res 298:193-196

Schmidt CJ, Fedayel GM (1995): The selective 5-HT2A receptor antagonist, MDL 100,907, increases dopamine efflux in the prefrontal cortex of the rat. Eur J Pharmacol 273(3):273-279

Seeman P, Lee T, Chau-Wong M, Wong K (1976): Antipsychotic drug doses and neuroleptic/ dopamine receptors. Nature 261:717-719

Snyder SH (1976): The dopamine hypothesis of schizophrenia: Focus on the dopamine receptor. Am J Psychiatry 1 33(2):197-202

Stockton ME, Rasmussen K (1996): Electrophysiological effects of olanzapine, a novel atypical antipsychotic, on A9 and A10 dopamine neurons. Neuropsychopharmacology 14(2):97-104

Volontè M, Monferini E, Cerutti M, Fodritto F, Borsini (1997): BIMG 80, a novel potential antipsychotic drug: Evidence for multireceptor actions and preferential release of dopamine in prefrontal cortex. J Neurochem 69:182-190

Weinberger DR (1987): Implications of normal brain development for the pathogenesis of schizophrenia. Arch Gen Psychiatry 44:660-669

White FJ, Wang RY (1983): Differential effects of classical and atypical antipsychotic drugs on A9 and A10 dopamine neurons. Science 221:1054-1057

Wolf MR, Roth RH (1987): Dopamine neurons projecting to the medial prefrontal cortex possess release-modulating autoreceptors. Neuropharmacology 26:1053-1059 